\title{
Vivências da bola: carreiras de futebolistas mulheres numa equipe do interior de São Paulo
}

\section{Female Football Experiences: careers of professional players in the State of São Paulo}

Caroline Soares de Almeida

Doutoranda em Antropologia Social - PPGAS/UFSC Pesquisadora do NAVI - Núcleo de Antropologia Visual da

UFSC almeidacaro182@gmail.com 
Proibido por décadas no Brasil, o Futebol Feminino ${ }^{1}$ só teve sua regulamentação em 1983. De lá pra cá, a modalidade tornou-se bastante praticada por mulheres no país. Surgiram clubes, campeonatos, mas o fantasma da proibição ainda permanece travestido na ideia de rejeição, sendo necessário grande empenho dessas atletas para que a categoria não permaneça invisibilizada. Esta série de fotografias tenta captar um pouco do cotidiano de futebolistas mulheres numa equipe de futebol do interior do estado de São Paulo chamada Associação Ferroviária de Esportes (AFE). O trabalho de campo foi realizado em 2016: um ano bastante conturbado também no Futebol Feminino, tendo como principal destaque, a realização dos Jogos Olímpicos do Rio de Janeiro e o destaque das jogadoras da Seleção.

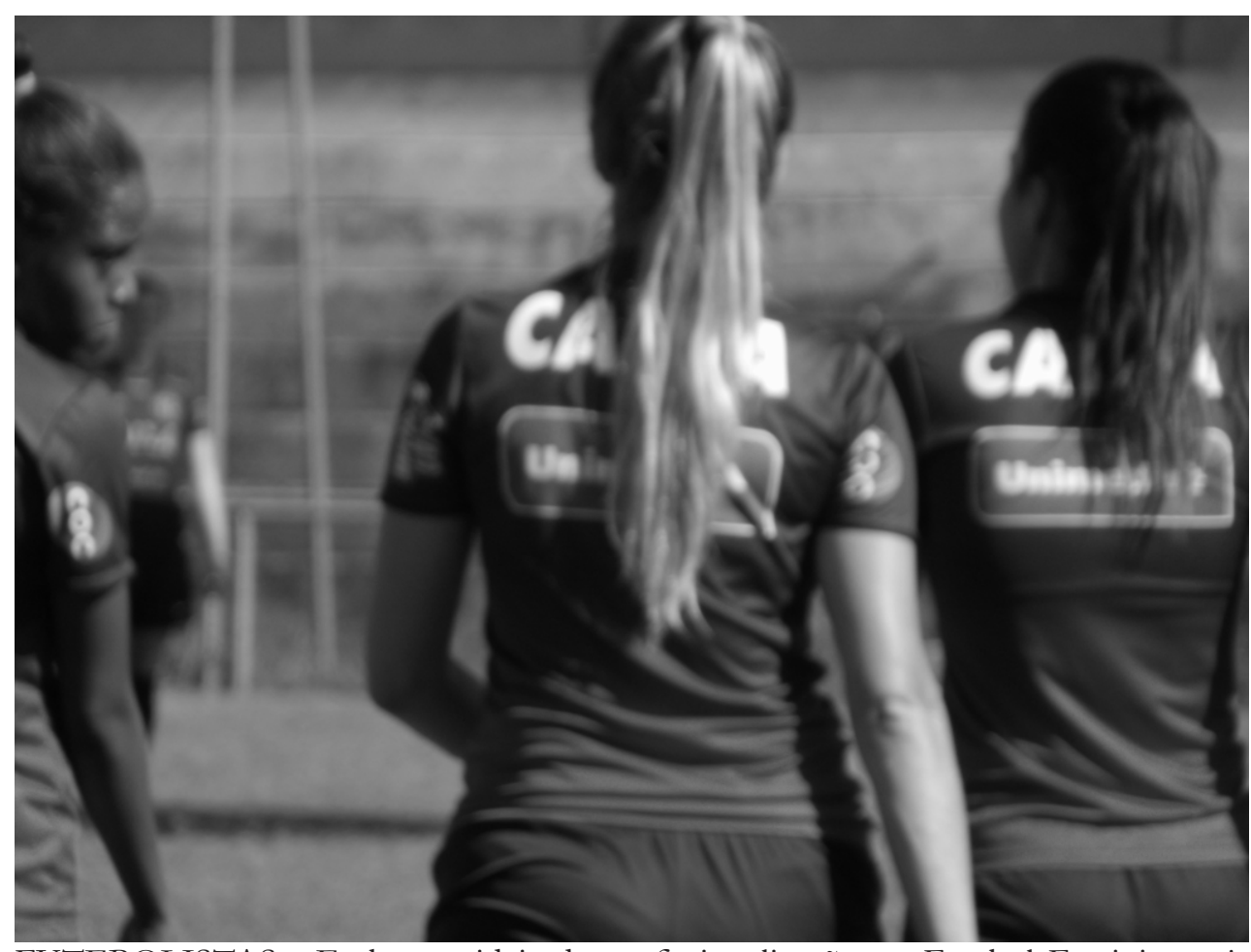

FUTEBOLISTAS - Embora a ideia de profissionalização no Futebol Feminino seja bastante discutida, existem mulheres que vivem e se dedicam exclusivamente ao futebol. Foto: Caroline Almeida. 


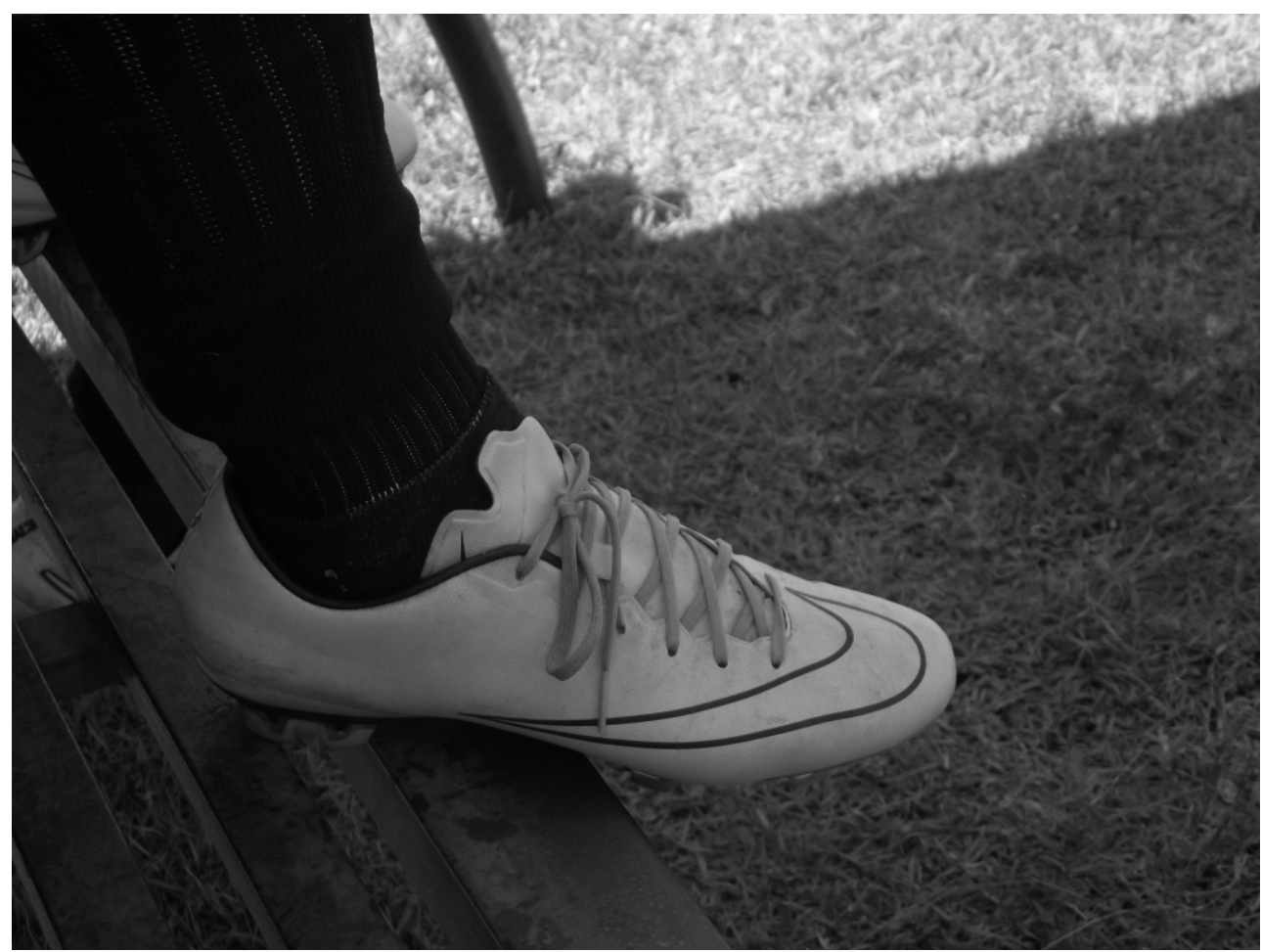

CHUTEIRA - A chuteira é o acessório mais importante para a/o futebolista. Deve ser confortável, ter boa durabilidade e ser bonita. Foto: Caroline Almeida.

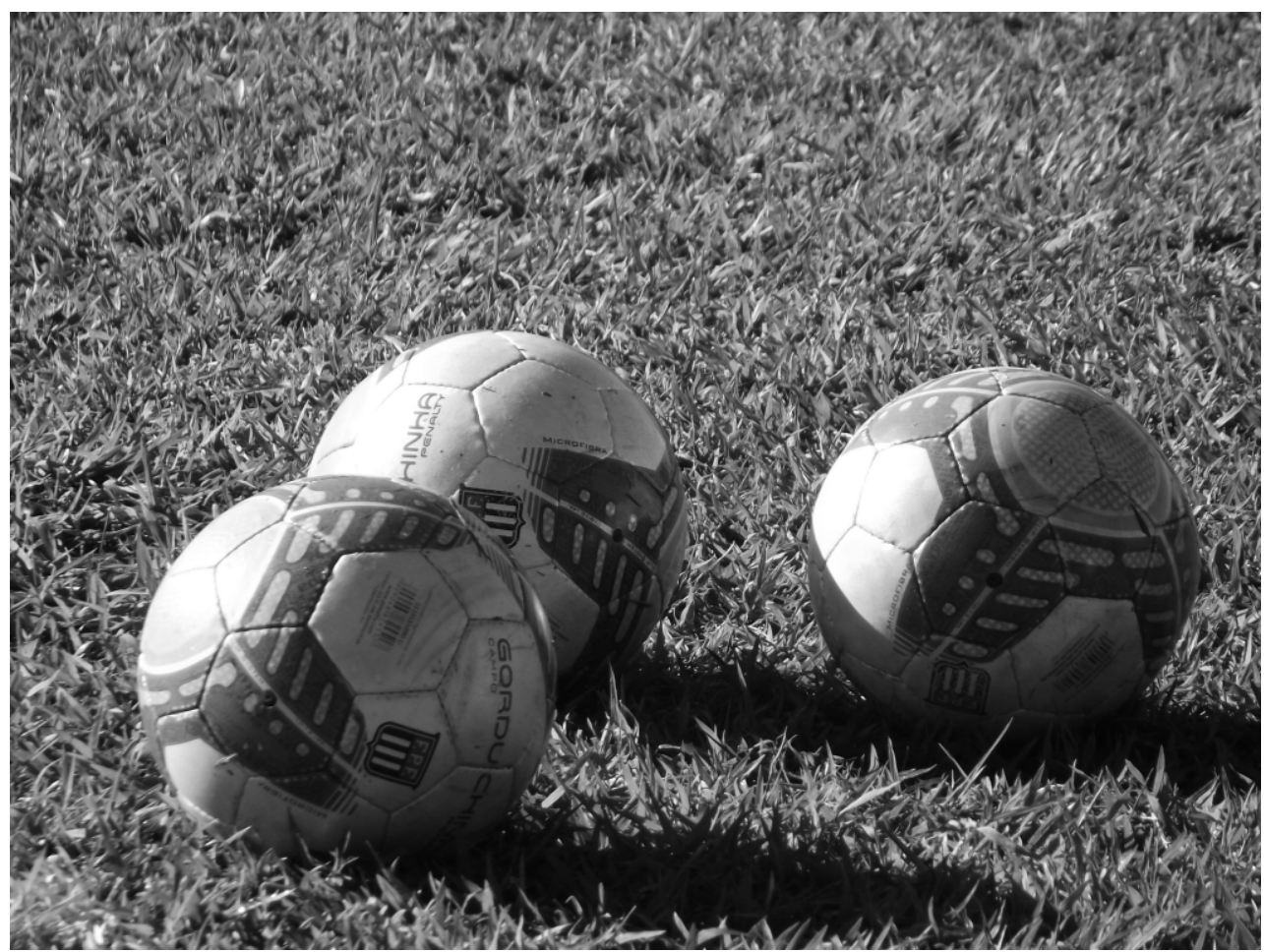

CAMPO - A equipe recebe as bolas que serão utilizadas no campeonato disputado neste caso, pelo Campeonato Paulista de Futebol Feminino. Foto: Caroline Almeida. 
Vivências da bola: carreiras de futebolistas mulheres numa equipe do interior de São Paulo

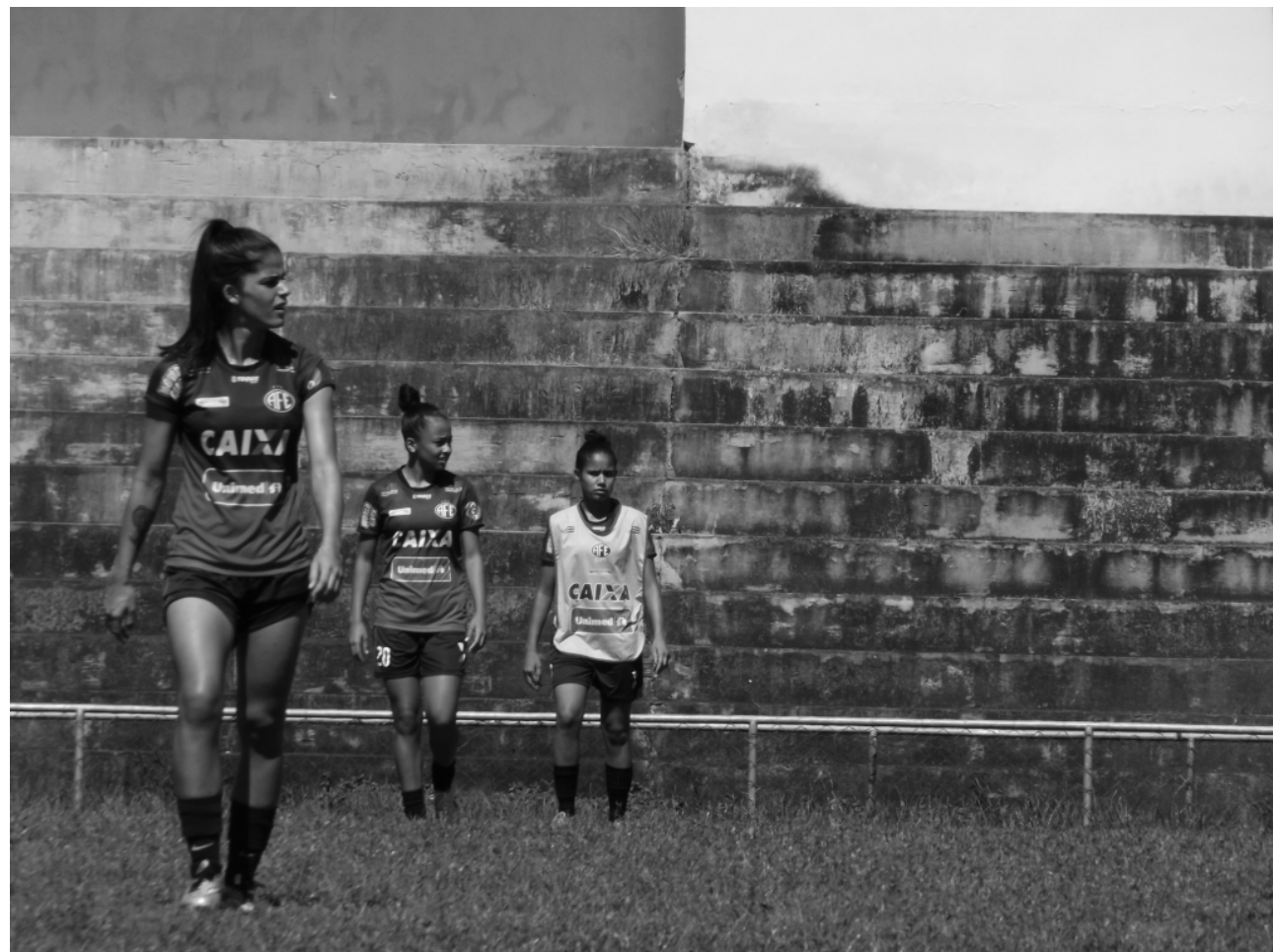

TREINO COLETIVO - Jogadoras trabalham com alinhamentos para o treino tático Foto: Caroline Almeida.

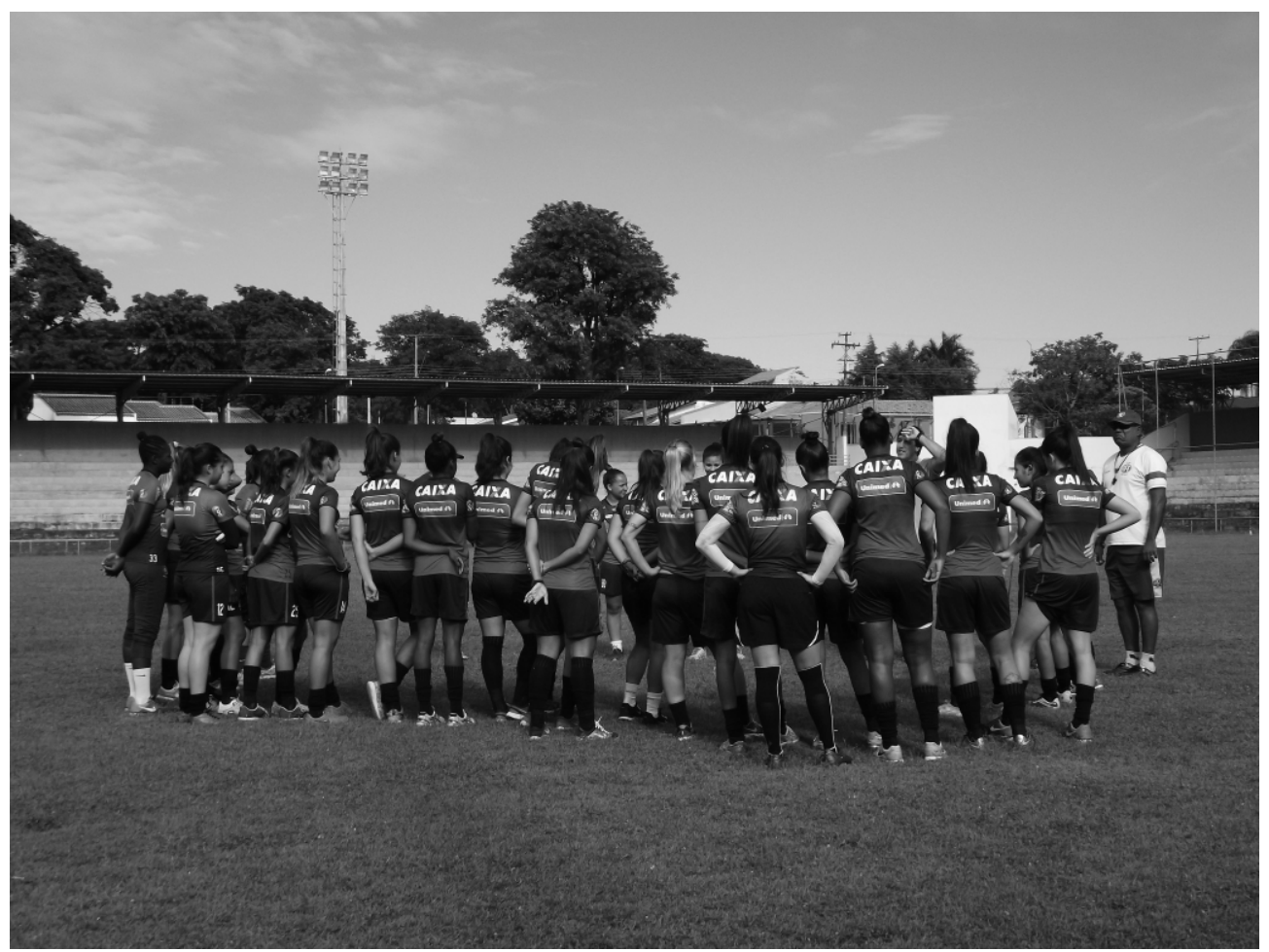

REUNIÃO - Momento em que a/o técnico/a aproveita para conversar com toda a equipe. Em geral, acontecem no início ou fim do treino coletivo. Foto: Caroline Almeida. 


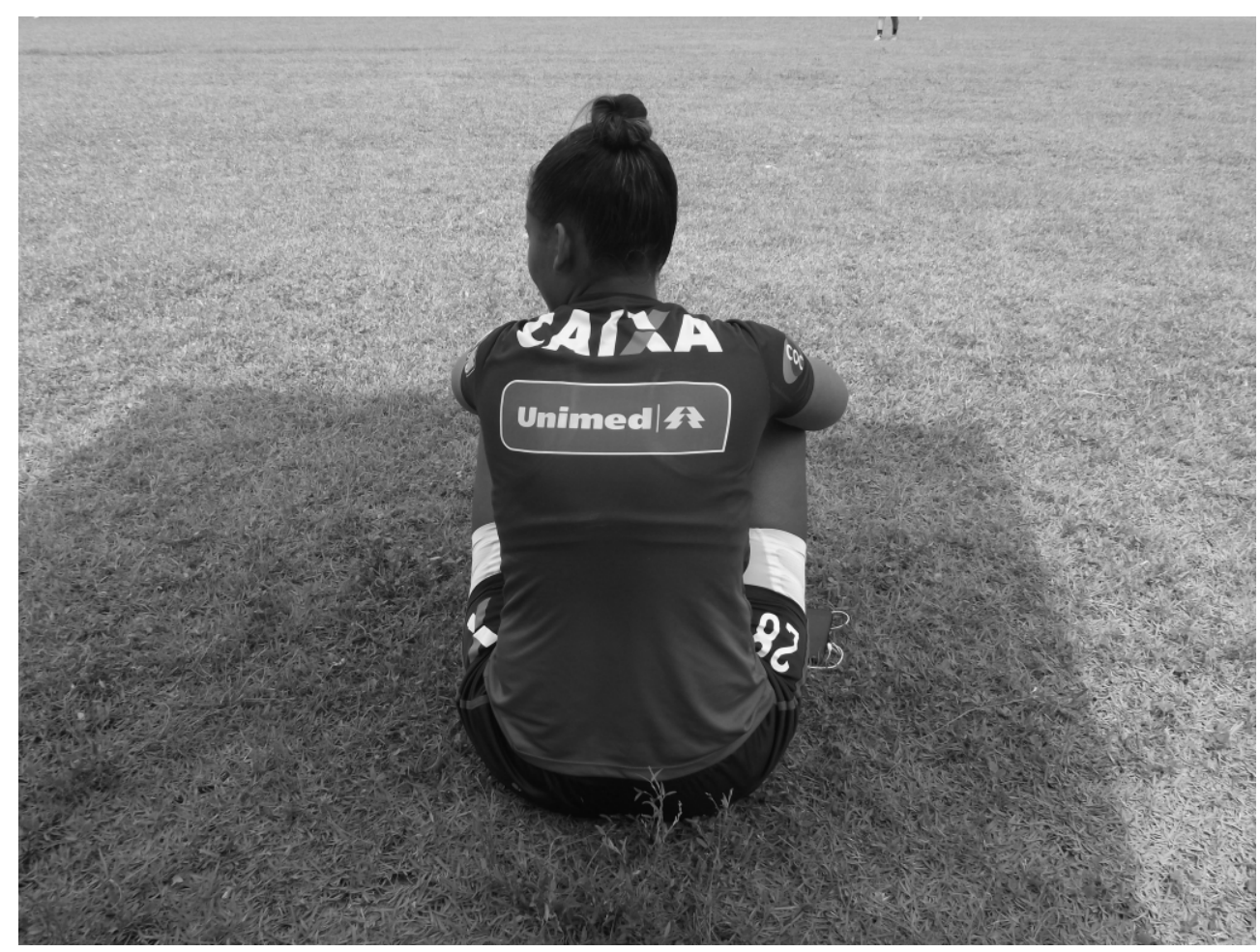

DESCANSO - Durante o treino tático, é feito um rodízio de jogadoras de forma a trabalhar individualmente as qualidades das peças (como são chamadas as futebolistas que compõem uma equipe). Esse é o momento para o descanso. Foto: Caroline Almeida.

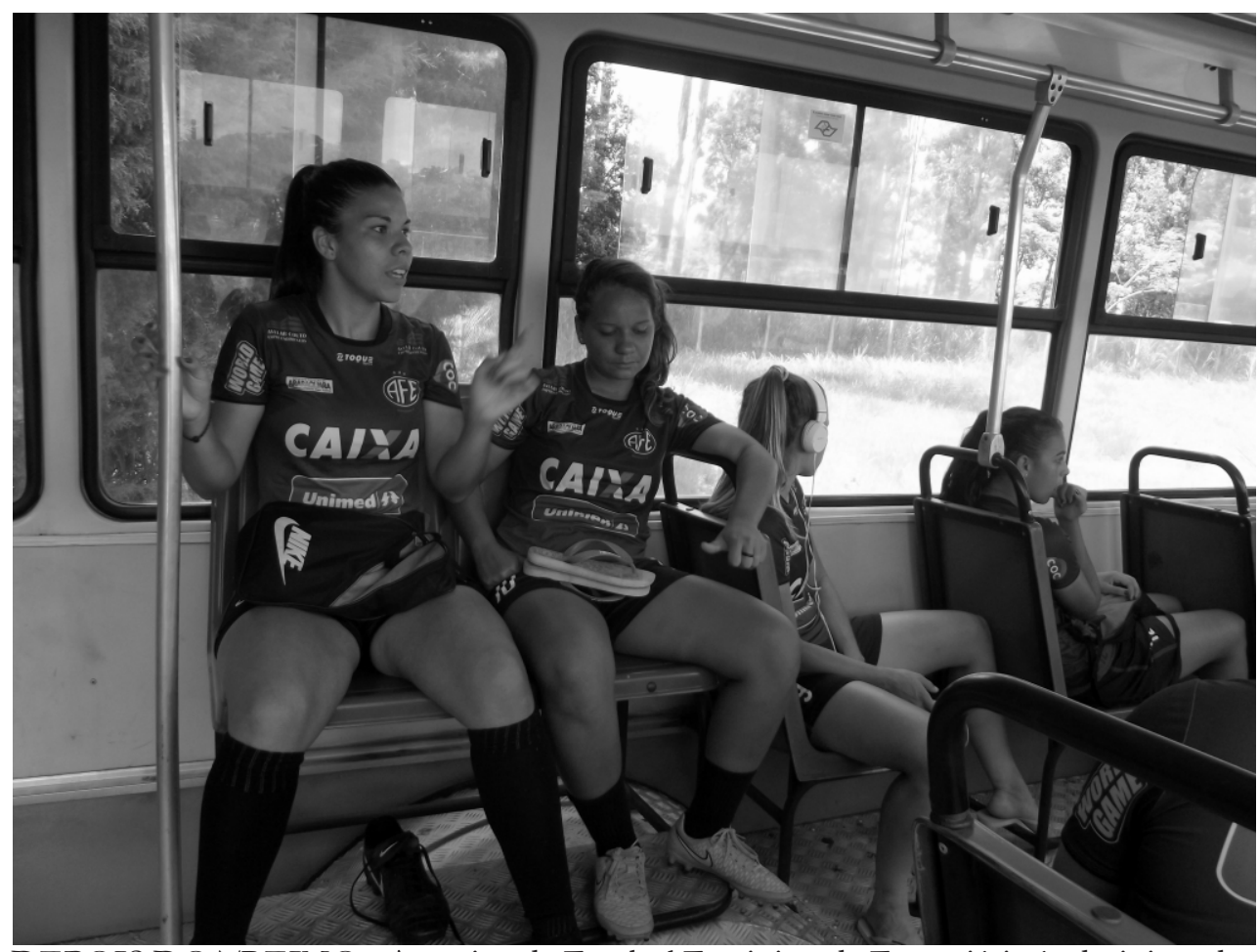

DEPOIS DO TREINO - A equipe de Futebol Feminino da Ferroviária é administrada e mantida pela Prefeitura de Araraquara (PMA/FUNDESPORT) e convênios com empresas privadas. Os ônibus que realizam o transporte das jogadoras pertencem à frota do município. Foto: Caroline Almeida. 


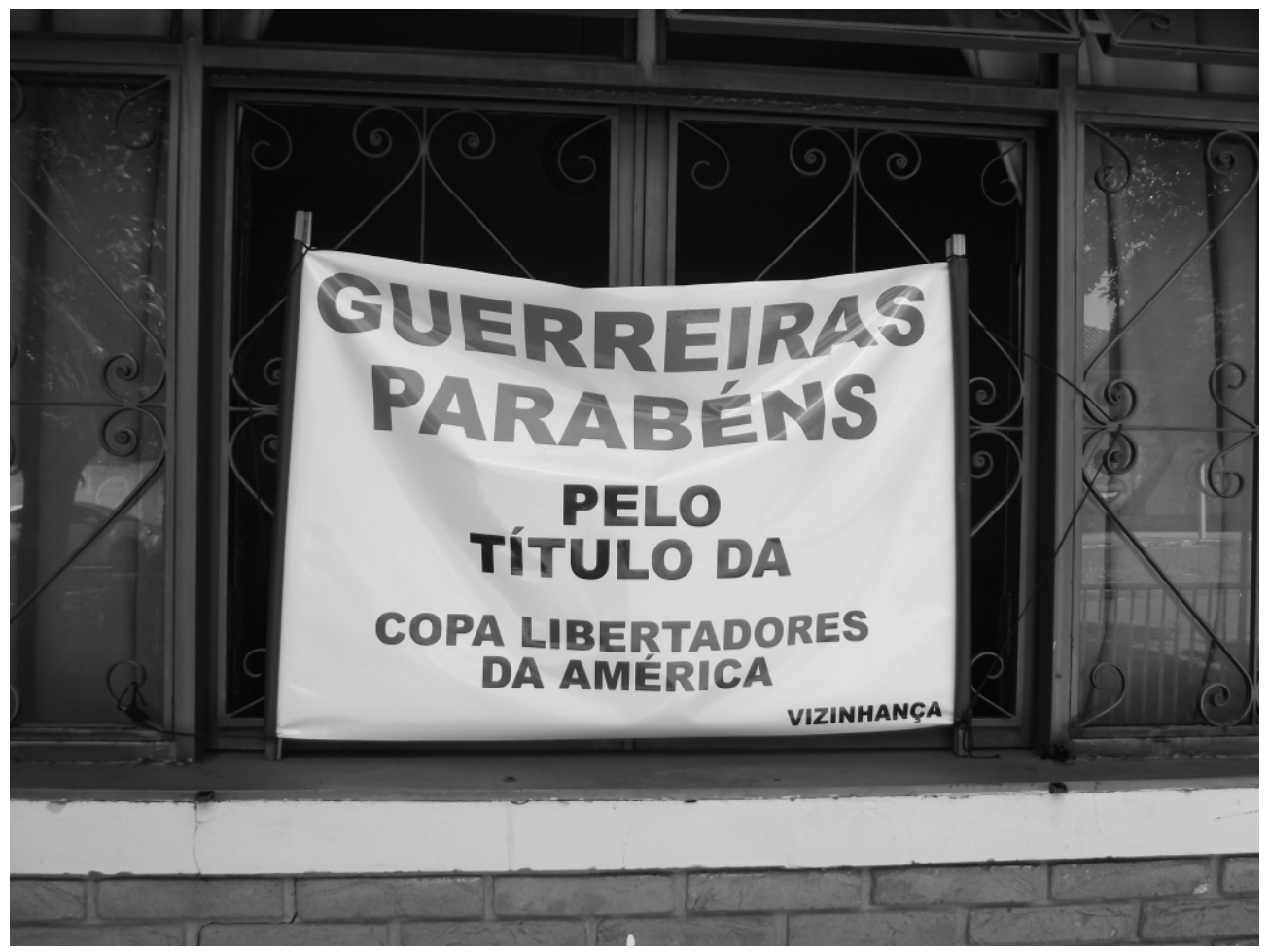

A CASA - Foto da antiga moradia da equipe, dividida entre, aproximadamente, vinte jogadoras. O clube foi campeão da Copa Libertadores Feminina 2015, realizada em Medellín. Foto: Caroline Almeida.

\section{Notas}

1. Futebol Feminino aparece aqui em maiúsculo dentro da uma ideia mais institucional de modalidade esportiva. 